\title{
Sperm Head Phenotype and Male Fertility in Ram Semen
}

3

4 A. Maroto-Morales ${ }^{\mathrm{a}}$, M. Ramón ${ }^{\mathrm{b}}$, Olga García-Álvarez ${ }^{\mathrm{a}}$, V. Montoro ${ }^{\mathrm{a}}$, A.J. Soler ${ }^{\mathrm{a}}$, M.R.

5 Fernández-Santos ${ }^{\mathrm{a}}$, E.R.S. Roldan ${ }^{\mathrm{c}}$, M.D. Pérez-Guzmán ${ }^{\mathrm{b}}$, J.J. Garde $^{\mathrm{a}^{*}}$

$6 \quad{ }^{a}$ SaBio IREC (UCLM-CSIC-JCCM), Campus Universitario s.n., 02071 Albacete, Spain

$7 \quad{ }^{\mathrm{b}}$ Regional Center of Animal Selection and Reproduction (CERSYRA) JCCM, 13300

8 Valdepeñas, Spain

$9{ }^{c}$ Reproductive Ecology and Biology Group, Museo Nacional de Ciencias Naturales (CSIC),

10 28006, Madrid, Spain

11 *Corresponding author:

12 José Julián Garde

13 ETSIA, Campus Universitario s.n., 02071-Albacete, Spain.

14 Phone: +34 967599 200+2829

15 Fax: +34967599238

16 e-mail: Julian.garde@uclm.es 


\section{Abstract}

Although there is ample evidence for the effects of sperm head shape on sperm function, its impact on fertility has not been explored in detail at the intraspecific level in mammals. Here, we assess the relationship between sperm head shape and male fertility in a large scale study in Manchega sheep (Ovis aries), which have not undergone any selection for fertility. Semen was collected from 83 mature rams and before insemination head shape were measured for five parameters: area, perimeter, length, width and $\mathrm{p} 2 \mathrm{a}\left(\right.$ Perimeter $^{2} / 2 * \pi *$ Area $)$ using a computer assisted sperm morphometry analysis. In addition, a cluster analysis using sperm head length and $\mathrm{p} 2 \mathrm{a}$ factor was performed in order to determine sperm subpopulations structure. Our results show the existence of 4 sperm subpopulations which present different sperm head phenotype: SP1 (large and round), SP2 (short and elongated), SP3 (shortest and round) and SP4 (large and the most elongated). No relationships were found between males' fertility rates and average values of sperm head dimensions. However, differences in fertility rates between rams were strongly associated to the proportion of spermatozoa in an ejaculate subpopulation with short and elongated heads $(P<0.001)$. These findings show how the heterogeneity in sperm head shape of the ejaculate has an effect on reproductive success, and highlight the important role of modulation of the ejaculate at the intraspecific level.

Keywords: fertility, ejaculate heterogeneity, sperm head shape, sperm morphometry, sheep. 


\section{Introduction}

In an attempt to improve the prediction of the fertilizing capacity of a male, mainly due to the widespread use of Assisted Reproductive Techniques (ART), many advances have been made on the development of in vitro sperm evaluation test together with the development of new statistical methods. Thus, it has achieved a significant improvement in the knowledge of sperm biology [1-3]. However, male fertility is still determined with a variable precision $[4,5]$. This fact makes necessary to continue looking for sperm features that allow us to predict the fertility potential of a sperm sample before using it by means of ART such as artificial insemination. Whereas semen samples with low sperm quality indicate low fertility rates, those samples with good quality not always ensure high fertility [6]. The emergence of Computer Assisted Semen Analysis (CASA) and flow cytometry techniques have allowed the identification of very different sperm attributes such as biochemical $[7,8]$, motility $[9,10]$ or morphometric parameters $[11,12]$ in a fast and objective manner. However, the interrelation between those sperm features assessed in the laboratory with reproductive performance is still controversial $[13,14]$.

Focusing on sperm morphology, mainly determined by the size and shape of sperm head, many studies have addressed how sperm design could affect the reproductive success of males showing conflicting results [15-22]. The majority of these studies have evaluated the relations between morphometric parameters and male fertility based on average values [15-19]. The use of average value of morphometric parameters oversimplifies analyses, considering the whole ejaculate as a homogeneous one. Consequently, the internal variability is not taken in to account, thus ignoring that fertilizing ability may vary depending on the sperm subpopulation under consideration [23]. Numerous studies have revealed the existence of morphometric sperm heterogeneity in several species [24-27]. In ram, our research group conducted a large scale study to identify in fresh ejaculates, for the first time in this species, the existence of different sperm subpopulation based on morphometric sperm head parameters [28], but the relationship 
between different head phenotype identified at the intraspecific level and their role on determining reproductive performance was not studied.

The aim of this work was to explore in a large sample of Manchega sheep (Ovis aries) the relationship between sperm head design and male fertility. The average fertility of Manchega rams following artificial insemination after an induced oestrus is about $42 \%$, ranging from $8 \%$ to 90\% [11]. Therefore, these males exhibit considerable diversity in sperm morphometric characteristics [28], being an excellent model to study possible associations between sperm traits and fertility. We employed computer-assisted sperm morphometry analyses together with clustering methods in order to (a) identify subpopulations based on sperm head morphometry, and (b) assess whether ram variability in fertility could be explained by differences in the proportions of such subpopulations.

\section{Materials and Methods}

\subsection{Animals}

Animal handling was performed in accordance with Spanish Animal Protection Regulation, RD 53/2013, which conforms to European Union Regulation 2010/63. A total of 83 adult males (age of males ranged from 1.5 to 3 years old) of the Manchega dairy sheep breed were used in this study. Males were kept at the Regional Centre of Animal Selection and Reproduction (CERSYRA, Spain), at the same environmental conditions. All males were trained for semen collection by artificial vagina and maintained a regime of regular collections (twice per week).

\subsection{Semen collection and evaluation}

For this study, one ejaculate was used per male, which was collected during the breeding season by using an artificial vagina. After collection, sperm quality was evaluated as described by Malo et al. [9]. The parameters analyzed were ejaculate volume (mL), sperm concentration (spz/mL), total sperm number in the ejaculate, wave motion (scale 1-5), percentage of motile sperm (\%), 
quality (vigor) of sperm movement (scale 1-5) and percentage of acrosome-intact spermatozoa (\%). The samples with a minimum of $75 \%$ motile sperm and wave motion of 3.5 , assessed subjectively, were used in this study to analyze sperm morphometry and to perform artificial inseminations (AIs). An aliquot of $5 \mu \mathrm{L}$ was taken from each ejaculate to assess sperm head morphometry characteristics. A computer-assissted sperm head morphometry analysis was performed as described by Maroto-Morales et al. [11]. Briefly, semen smears were air-dried and stained using a Hemacolor (Merck) procedure. Stained sperm samples were permanently mounted to the slide with a coverslip and dibutil phatalate xylene (DPX). Stained slides were used to perform the sperm analysis using the morphometry module of a commercially available system (SpermClass Analyser ${ }^{\circledR}$, SCA, Microptic, Barcelona, Sapina). The illumination source was centered and the intensity of the bulb and the gain and offset of the camera were standardized for all samples. The morphometric dimensions for head area $\left(\mathrm{A}, \mu \mathrm{m}^{2}\right)$, head perimeter $(\mathrm{P}, \mu \mathrm{m})$, head length $(\mathrm{L}, \mu \mathrm{m})$, head width $(\mathrm{W}, \mu \mathrm{m})$ and a shape factor $\mathrm{p} 2 \mathrm{a}\left(\mathrm{P}^{2} / 4 \pi \mathrm{A}\right)$, also known as roundness, were acquired from 120-125 images assuring a minimum of 100 properly measured sperm heads. The shape feature p2a compares the perimeter of an object to its area [29]. This parameter takes a minimum value of 1 for a circle, and as the value of $\mathrm{p} 2 \mathrm{a}$ increases, the shape becomes more elongated.

\subsection{Artificial insemination trials}

After semen collection and evaluation, ejaculates from the 83 rams were used to perform a total of 1024 AIs. Each female was inseminated once with spermatozoa from one ram and each male was used to inseminate a minimum of 12 ewes. A detailed description of methods used for semen processing and AI can be found elsewhere [30]. To control for the effects of sperm number on fertility [31], the total number of spermatozoa inseminated was kept constant at $400 \mathrm{x}$ $10^{6}$ spermatozoa for all the inseminations performed. No effect of number of ewes inseminated by each ram was found on the rams' fertility rates $(P=0.89)$. To minimize the potential effect of 
female fertility on the results obtained, all ewes had their oestrous cycles synchronized to avoid the confounding effects of females being inseminated at different times in relation to ovulation (for details see [30]). We considered that a male scored a successful fertilization when the ewe became pregnant.

\subsection{Statistical Analysis}

All statistical analyses were carried out using the $\mathrm{R}$ version 3.0.2 statistical environment [R Development Core Team 2013]. Where applicable, $P<0.05$ was considered statistically significant, unless otherwise stated.

Fertilization success for every ram was calculated as number of ewes pregnant/number of ewes inseminated $x$ 100. Since AI outcome may depend on several factors, the herd, year and season of insemination, the technician performing the AI and the ewe inseminated were considered in this study as potential factors of variation and were included in an initial analysis. The AI outcome was "1" if an ewe become pregnant and "0" if not, and the effects of the factors mentioned above were estimated using a general linear regression model (GLM). To remove the variation due to these factors when assessing the relationship between fertility and sperm morphometry, the subsequent analyses were performed using the residuals from the first analysis plus the average AI outcome of the population to express adjusted fertility outcomes in the raw scale.

Regression analyses were carried out to examine relationships between male phenotypic traits, including sperm head shape, on male fertility. For sperm head morphometry, two different analyses were performed, one of them using average values for the different sperm head measures, and another one considering the sperm subpopulations distribution within the ejaculate. For the latter, a cluster procedure using a total of 9448 spermatozoa was performed following a multi-step process. A detailed description of the methodology used for the clustering analysis has been presented previously [28,32]. Briefly, sperm head subpopulations were 
identified in two sequential steps: (i) a nonhierarchical clustering analysis using sperm head length and the p2a shape factor as initial classificatory variables; and (ii) a hierarchical clustering analysis using the groups resulting from the previous step to obtain the final number of clusters (i.e., sperm head subpopulations). After cluster analysis, the relationships between the proportion of each of the subpopulations present in the ejaculates and male fertility were examined.

\section{Results}

The routine parameters of semen samples recovered by artificial vagina had, on average, a volume of $1.01 \pm 0.38 \mathrm{~mL}$, a concentration of $4715 \pm 789.04 \times 10^{6} \mathrm{spz} / \mathrm{mL}$, and a total sperm number of $4726 \pm 1895.93 \times 10^{6}$ spermatozoa, the latter two variables showing a considerable variation between males. In addition, the percentages of motile spermatozoa and percentage of sperm with intact acrosomes were high on average $(83.79 \pm 7.15 \%$ and $93.89 \pm 3.35 \%$, respectively). No significant correlations were found between males' fertility rates and average values of routine parameters presented

Regarding sperm head morphometry, we searched for possible correlations between mean morphometry values and fertility. So, the mean values for sperm head morphometry parameters of the 83 rams included in this study were $8.87 \pm 0.24 \mu \mathrm{m}$ for length, $4.79 \pm 0.20 \mu \mathrm{m}$ for width, $34.90 \pm 2.09 \mu \mathrm{m}^{2}$ for area, $26.95 \pm 1.41 \mu \mathrm{m}$ for perimeter, $1.67 \pm 0.17$ for $\mathrm{p} 2 \mathrm{a}$. None of the average morphometric parameters were significantly correlated with males' fertility.

Finally, we examined how the males' sperm subpopulation distribution was related to their fertility. Four sperm subpopulations (SP) were identified, clearly differentiated by their sperm head length and the p2a values (Figure 1). Average percentage of spermatozoa in each subpopulation (i.e., group size) varied from $1.7 \%$ (SP4) to $47.9 \%$ (SP2) with a wide range of spermatozoa in each subpopulation when all rams were considered (Table 1). The characteristics of each of the sperm subpopulations were as follows: Subpopulation 1 (SP1) included 
spermatozoa whose sperm head was long (average length of $9.5 \pm 0.3 \mu \mathrm{m}$ ) and wide (average p2a of $1.6 \pm 0.2$ ). Subpopulation 2 (SP2) included spermatozoa whose head was short (average length $=8.9 \pm 0.2 \mu \mathrm{m}$ ), and elongated (average p2a $1.8 \pm 0.2$ ). Subpopulation 3 (SP3) was characterized by spermatozoa with the shortest head dimensions (average length $8.3 \pm 0.3 \mu \mathrm{m}$ ) and wide (average p2a $1.60 \pm 0.21$ ). Finally, Subpopulation 4 (SP4) included spermatozoa whose sperm head length $(9.26 \pm 0.42 \mu \mathrm{m})$ and p2a $(2.49 \pm 0.27)$ were the highest. Our results revealed a significant positive correlation $(\mathrm{r}=+0.49 ; P<0.001)$ between the percentage of spermatozoa in subpopulation SP2 and male fertility (Figure 2b), and there were no significant relationships between the percentages of spermatozoa in the other subpopulations with fertility (Figure $2 \mathrm{a}, \mathrm{c}$ and d).

\section{Discussion}

This work examined at the intraspecific level, in a large scale experiment, the relationship between sperm shape and male fertility. Whereas no correlations were found between average values of sperm head morphometric parameters and male fertility, the subpopulation structure of the ejaculate, based on sperm shape, was associated to reproductive success.

Our experimental design was aimed at eliminating several factors known to influence field fertility $[33,34]$ as a way to assure that differences in the fertility were due to sperm morphometric factors studied. Thus, (i) different environmental effects (herd management factors, year and season of artificial insemination and technician performing the inseminations) were quantified and removed from male fertility values; (ii) all ewes had their estrous cycles synchronized avoiding the confounding effects of insemination time and (iii) a large number of males and inseminations were used, thus minimizing the potential effect of female fertility on the results obtained. In addition, in order to control the well-known effects of sperm numbers on 
192

193

194

195

196

197

198

199

200

201

202

203

204

205

206

207

208

209

210

211

212

213

214

215

216

fertility [31], the total number of spermatozoa was kept constant in all the artificial inseminations (AIs) performed.

Some researchers have reported the correlation between sperm design and sperm function $[15,20,35,36]$. However, the role of sperm design as a determinant of fertilization success has yielded variable results. Thus, while some studies have shown significant correlations between the phenotype of the sperm head and fertility [16,17,20,22,37], others found no evidence for these associations $[18,19]$. It is possible that in many studies the lack of a clear relationship could be due to the fact that sperm linear dimensions or average values of sperm parameters were used. In the present work when we tested the effect of average values of sperm head shape on fertility no relation was found, neither relationship between semen quality parameters routinely evaluated (volume, sperm concentration, total sperm number, the proportion of spermatozoa with intact acrosomes and the proportion of motile cells) with fertility was observed. The use of mean values to assess the reproductive performance of a sperm sample or a male is considered incomplete since most of the data's variability is not taken into account, losing a large amount of information that can lead to misleading analysis. Thus, our results confirm that ejaculates should not be regarded as a homogenous population [23,38,39].

The heterogeneity of the ejaculate is characterized by the presence of different sperm subpopulations [11,40-42], existing different statistical methods for obtaining groups of spermatozoa that share similar features [32,42-45]. Other researchers who assessed the role of sperm head morphometry and sperm function have used a Fourier analysis $[36,46]$. This latter is quite complex and reported results difficult to explain [46] compared with that used in the present study. However, both analysis show similar sperm head shape in those males with higher fertility [47]. Thus, for characterization of sperm subpopulations, we have used computerassisted sperm analysis together with multivariate cluster analyses which have allowed us to group the observations into subsets (called subpopulations). Cluster analysis is perfectly suited to 
resolve the heterogeneity of sperm form data in discrete subpopulations, helping to take advantage of the information contained in computer-assisted sperm analysis datasets [48]. Our results showed four subpopulations with different morphometric characteristics. This number of subpopulations agrees with those reported in other mammalian species [22,27,49]. However, in ram, the few studies found so far $[22,37,50]$ have reported different number of sperm subpopulations describing the existence of 3 subpopulation, whereas Marti et al. [51] in cryopreserved ram sperm samples reported 3 and 4 sperm subpopulations for younger and older rams, respectively. Their results have differed from those obtained in our work, mainly due to that theses authors have performed a PCA previously to the clustering analysis and the subpopulations have been identified by using other sperm morphometric parameters as classifiers, and also different sheep breeds and sperm samples (cryopreserved) were used. Another fact to highlight about these studies $[22,37,50]$ is the low number of animals used to carry them out, only 8 rams in those conducted by Vicente-Fiel et al. [50] and Yániz et al. [22] whereas 24 males were used by de Paz et al. [37], which leading to draw slightly robust conclusions. In our work, 83 rams were used which we consider to be an adequate representation of the species that allow us to obtain conclusive results.

It is known that spermatozoa from different sperm subpopulations respond differently to procedures such as cryopreservation or capacitation conditions $[10,12,52,53]$. And, therefore, it is also reasonable to consider that sperm subpopulation structure may be related to fertility. Thus, recent studies in red deer [20] and sheep [22,37] have demonstrated the relations between sperm morphometric parameters and reproductive performance after taking into account variations among spermatozoa in the ejaculate. These results are similar to those found in this work where an association was found between a particular type of sperm subpopulation with reproductive performance. In addition, to our knowledge, this is the first study where a possible 
relation between morphometric sperm subpopulations and fertility has been investigated in a large scale at intraspecific level.

In the present work the proportion of spermatozoa with elongated heads (SP 2) was associated with males' fertility rates, revealing that indeed the relationship between sperm head shape and fertilization was clear when the heterogeneity of semen based on sperm head morphometry was considered. In agreement with our results, Ramon et al [20] observed that red deer males with high fertility rates had ejaculates with high percentages of fast and linear spermatozoa with small and elongated head. Sperm head elongation may play an aimportant role by making sperm more hydrodynamically-efficient which, in turn, may influence sperm fertilization ability. Sperm with elongated heads may be faster $[9,20]$ because they could have less resistance to forward progression (i.e., less drag) and may expend less energy. The latter could result in more sperm if there is a constraint to increases in sperm length or sperm may have longer lifespan if energy reserves last longer or are used more efficiently [54]. In addition, and due to most of the sperm head is occupied by the nucleus so its compactness can influence sperm head shape, evidence has been presented supporting the involvement of protamines in sperm head shaping, leading to smaller and more elongated sperm heads $[35,55]$. On the contrary, different features of sperm head, compared with those obtained in our study, have been recently reported in ovine [21] in males with higher fertility rates, although these authors only used the sperm nuclear size and no information about the dimensions of acrosome or cytoplasm, which could influence in the sperm head shape and size, were taken into account.

Hence, the correlation found in our study between sperm head features (size and shape) and field fertility revealed, only when heterogeneity of the sperm sample is considered, how subtle differences in sperm design seem to have a great impact upon sperm performance. This heterogeneity of the ejaculates is now widely recognized and it is thought that this diversity is advantageous for males engaging in sperm competition [56]. The species used in this work 
(Manchega sheep (Ovis aries)) have a polyandrous mating pattern which would result in sperm competition and evolution of reproductive traits by this selective force. Consistent with sperm competition theory, rams have very large testes in relation to their body mass [57]. So, it is possible that the level of competition between sperm of rival males for fertilization has influenced the evolution of some sperm traits producing changes in sperm head design [58]. Thus, the heterogeneity of ram ejaculates found in our study may reflect adaptations to conditions under which sperm perform and to ensure survival of spermatozoa in fertilization environments, maximizing fertilizing capacity [23]. Future studies should be conducted about the role of sperm competition on the evolution of sperm design.

\subsection{Conclusions}

In conclusion, we found that differences in fertility rates between males were related to the proportion of sperm subpopulations whereas no relationships were detected when average morphometric values were used. Thus, male fertility seems to associate to the proportion of a particular type of sperm subpopulation (spermatozoa with short and elongated head (SP2)) that average values do not reflect. This population structure could be closely related to the overall functional levels of the entire ejaculate, of which the sperm shape would be a very valuable indicator. Therefore, a more in-depth analysis of the subtle differences in the distribution of subpopulations, together with functional tests, could aid in the design of strategies for the prediction of the fertility of ram ejaculates.

\section{Acknowledgements}

AGRAMA is gratefully acknowledged for allowing the insemination of ewes. 


\section{References}

293 [1] DeJarnette JM, Marshall CE, Lenz RW, Monke DR, Ayars WH, Sattler CG. Sustaining the

294

295

296

297

298

299

300

301

302

303

304

305

306

307

308

309

310

311

312

313

314

315
Fertility of Artificially Inseminated Dairy Cattle: The Role of the Artificial Insemination Industry. J Dairy Sci 2004;84:93-104.

[2] Mocé E, Graham JK. In vitro evaluation of sperm quality. Anim Reprod Sci 2008;105:10418.

[3] Palacín I, Yániz JL, Fantova E, Blasco ME, Quitín-Casorrán FJ, Sevilla-Mur E, Santolaria P. Factors affecting fertility after insemination with cooled semen in meat sheep. Anim Reprod Sci 2012;132:139-44.

[4] Rodríguez-Martínez H. Laboratory semen assessment and prediction of fertility: still utopia? Reprod Domest Anim 2003;38:312-8.

[5] Dejarnette JM. The effect of semen quality on reproductive efficiency. Vet Clin North Am Foo Anim Parct 2005;21:409-18.

[6] Colenbrander B, Gadella BM, Stout TAE. The predicitive value of semen analysis in the evaluation of stallion fertility. Reprod Dom Anim 2003;38:305-11.

[7] Januskauskas A, Johannisson A, Soderquist L, Rodriguez-Martinez H. Assessment of sperm characteristics post-thaw and response to calcium ionophore in relation to fertility in Swedish dairy AI bulls. Theriogenology 2000;53: 859-75.

[8] Martínez-Pastor F, Mata-Campuzano M, Álvarez-Rodríguez M, Álvarez M, Anel L, de Paz P. Probes and Techniques for Sperm Evaluation by Flow Cytometry. Reprod Dom Anim 2010;45:67-78.

[9] Malo A, Garde JJ, Soler AJ, García AJ, Gomendio M, Roldan ERS. Male fertility in natural populations of red deer is determined by sperm velocity and the proportion of normal spermatozoa. Biol Reprod 2005;72:822-29. 
[10] García-Álvarez O, Maroto-Morales A, Ramón M, Del Olmo E, Jiménez-Rabadán P,

Fernández-Santos MR, Anel-López L, Garde JJ, Soler AJ. Dynamics of sperm subpopulations based on motility and plasma membrane status in thawed ram spermatozoa incubated under conditions that support in vitro capacitation and fertilization. Reprod Fertil Dev 2014; 26: 72532.

[11] Maroto-Morales A, Ramon M, Garcia-Alvarez O, Soler AJ, Esteso MC, Martinez-Pastor F, Perez-Guzman MD, Garde JJ. Characterization of ram (Ovis aries) sperm head morphometry using the Sperm-Class Analyzer. Theriogenology 2010;73:437-48.

[12] Ramón M, Pérez-Guzmán MD, Jiménez-Rabadán P, Esteso MC, García-Álvarez O, Maroto-Morales A, Anel-López L, Soler AJ, Fernández-Santos MR \& Garde JJ. Sperm cell population dynamics in ram semen during the cryopreservation process. PLOS ONE 2013;8 e59189.

[13] Rodriguez-Martinez H, Barth A. In vitro evaluation of sperm quality related to in vivo function and fertility. Soc Reprod Fertil Suppl 2007;64:39-54.

[14] Rodriguez-Martinez H. State of the art in farm animal sperm evaluation. Reprod Fert Dev 2007;19:91-101.

[15] Malo A, Gomendio M, Garde JJ, Lang-Lenton B, Soler AJ, Roldan ERS. Sperm design and sperm function. Biol Lett 2006;2:246-9.

[16] Hirai M, Boersma A, Hoeflich A, Wolf E, Foll J, Aumüller TR, Braun J. Objectively measured sperm motility and sperm head morphometry in boars (Sus scrofa): relation to fertility and seminal plasma growth factors. J Androl 2001; 22:104-10.

[17] AI-Makhzoomi A, Lundeheim N, Haard M, Rodríguez-Martínez H. Sperm morphology and fertility of progeny-tested AI dairy Bulls in Sweden. Theriogenology 2008;70:682-91.

[18] Gravance CG, Casey ME, Casey PJ. Pre-freeze bull sperm head morphometry related to post-thaw fertility. Anim Reprod Sci 2009;114:81-8. 
[19] Marco-Jiménez F, Vicente JS, Lavara R, Balasch S, Viudes-de-Castro MP. Poor prediction value of sperm head morphometry for fertility and litter size in rabbit. Reprod Domest Anim 2010;45:118-23.

[20] Ramón M, Soler AJ, Ortiz JA, García-Álvarez O, Maroto-Morales A, Roldan ER,Garde JJ. Sperm population structure and male fertility: an intraespecific study of sperm design and velocity in red deer. Biol Reprod 2013;89:110.

[21] Vicnete-Fiel S, Palacín I, Santolaria P, Fantova E, Quintín-Casorrán FJ, Sevilla-Mur E, Yániz JL. In vitro assessment of sperm quality from rams of high and low field fertility. Anim Reprod Sci 2014;146:15-20.

[22] Yániz JL, Palacín I, Vicente-Fiel S, Sánchez Nadal JA, Santolaria P. Sperm population struture in high and low field fertility rams. Anim Reprod Sci 2015;154:128-34.

[23] Ramón M, Jiménez-Rabadán P, García-Álvarez O, Maroto-Morales A, Soler AJ, Fernández-Santos MR, Guzmán MD, GardeJJ. Undertanding sperm heterogenetiy: Biological and practical implications. Reprod. Domestic Anim 2014;49:30-6.

[24] Thurston LM, Watson PF, Holt WV. Sources of variation in the morphological characteristics of sperm subpopulations assessed objectively by a novel automated sperm morphology analysis system. J Reprod Fertil 1999;117:271-80.

[25] Buendía P, Soler C, Paolicchi F, Gago G, Urquieta B, Pérez-Sánchez F, Bustos-Obregón E. Morphometric characterization and classification of alpaca sperm heads using the Sperm-Class Analyzer computer-assisted system. Theriogenology 2002;57:1207-18.

[26] Álvarez M, García-Macías V, Martínez-Pastor F, Martínez F, Borragán S, Mata M, Garde J, Anel L, De Paz P. Effects of cryopreservation on head morphometry and its relation with chromatin status in brown bear (Ursus arctos) spermatozoa. Theriogenology 2008;70:1498-506. 
[27] Esteso MC, Fernández-Santos MR, Soler AJ, Montoro V, Martínez-Pastor F, Garde JJ. Identification of sperm-head subpopulations in Iberian red deer epididymal sperm samples. Reprod. Dom Anim 2009;44: 206-11.

[28] Maroto-Morales A, Ramón M, García-Álvarez O, Soler AJ, Fernández-Santos MR, Roldan ERS, Gomendio M, Pérez-Guzmán MD, Garde JJ. Morphometrically-distinct Sperm

Subpopulations defined by a Multi-step Statistical procedure in Ram Ejaculates: Intra- and Inter individual variation. Theriogenology 2012;77:1529-39.

[29] Sailer BL, Jost LK, Evenson DP. Bull sperm head morphometry related to abnormal chromatin structure and fertility. Cytometry 1996;24:167-73.

[30] Gómez-Brunet A, Santiago-Moreno J, Montoro V, Garde J, Pons P, Gonzaléz-Bulnes A, López-Sebastián A. Reproductive performance and progesterone secretion in estrus-induced Manchega ewes treated with hCG at the time of AI. Small. Rumin Res 2007; 71:117-22. [31] Stratman FW, Self HL. A comparison of natural mating with artificial insemination and the influence of volume and sperm numbers on conception rate and fertility levels in sows. J Anim Sci 1959;18:1556-7.

[32] Martinez-Pastor F, Garcia-Macias V, Alvarez M, Herraez P, Anel L, de Paz P. Sperm subpopulations in Iberian red deer epididymal sperm and their changes through the cryopreservation process. Biol Reprod 2005;72:316.

[33] Amann RP, DeJarnette JM. Impact of genomic selection of AI dairy sires on their likely utilization and methods to estimate fertility: a paradigm shift. Theriogenology 2012;77:795-817. [34] Palacín I, Yániz JL, Fantova E, Balsco ME, Quintín-Casorrán FJ, Sevilla-Mur E, SAntolaria P. Factors affecting fertility after cervical insemiantion with cooled semen in meat sheep. Anim Reprod Sci 2012;132:139-44.

[35] Lüke L, Vicens A, Tourmente M, Roldan ERS. Evolution of Protamine Genes and changes in sperm head phenotype in rodents. Biol. Reprod 2014;90:1-8. 
[36] Thurston LM, Watson PF, Mileham AJ, Holt WV. Morphologically distinct sperm subpopulations defined by fourier shape descriptors in fresh ejaculates correlate with variation in boar semen quality following cryopreservation. J Androl 2001;22;382-94

[37] de Paz P, Mata-Campuzano M, Tizado EJ, Alvarez M, Alvarez-Rodríguez M, Herraez P, Anel L. The relationship between ram sperm head morphometry and fertility depends on the procedures of acquisition and analysis used. Theriogenology 2011;76:1313-25.

[38] Mortimer ST. A critical review of the physiological importance and analysis of sperm movement in mammals. Hum Reprod Update 1997;3: 403-39.

[39] Mortimer ST. CASA—practical aspects. J Androl 2000 ;21:515-24.

[40] Holt VW, Van Look. Concepts in sperm heterogeneity, sperm selection and sperm competition as biological foundations for laboratory tests of semen quality. Reproduction 2004;127:527-35.

[41] Martínez-Pastor F, Cabrita E, Soares F, Anel L, Dinis MT. Multivariate cluster analysis to study motility activation of Solea senegalensis spermatozoa: A model for marine teleosts. Reproduction 2008;135:449-59.

[42] Martínez-Pastor F, Tizado EJ, Garde JJ, Anel L, de Paz P. Statistical series: opportunities and challenges of sperm motility subpopulation analysis. Theriogenology 2011;75:783-95. [43] Martínez-Pastor F, García-Macías V, Álvarez M, Herráez P, Anel L, de Paz P. Sperm subpopulations in Iberian Red Deer epididymal sperm and their changes through the cryopreservation process. Biol Reprod 2005;72:316-27.

[44] Núñez-Martínez I, Moran JM, Peña FJ. Two-Step cluster procedure after principal component analysis identifies sperm subpopulations in canine ejaculates and its relation to cryoresistance. J Androl 2006;27:596-603.

[45] Ramón M, Martínez-Pastor F, García-Álvarez O, Maroto-Morales A, Soler AJ, JiménezRabadán P, Fernández-Santos MR, Bernabéu R, Garde JJ. Taking advantage of the use of 
supervised learning methosd for characterization of sperm popultaion struture related with freezabitlity in the Iberian red deer. Theriogenology 2012;77:1661-72.

[46] Ostermeier GC, Sargeant GA, Yandell BS, Parrish JJ. Measurement of bovine sperm nuclear shape using fourier harmonic amplitudes. J Androl 2001a;22:584-94.

[47] Ostermeier GC, Sargeant GA, Yandell BS, Evenson DP, Parrish JJ. Relationship of bull fertility to sperm nuclear shape. J Andro 2001b;22:595-603.

[48] Evans JP, Lorenzo Z, Francescato S, Pilastro A. Directional post-copulatory sexual selection revealed by artificial insemination. Nature 2003;241:360-3.

[49] Rubio-Guillén J, González D, Garde JJ, Esteso MC, Fernández-Santos MR, Rodríguez-Gil

JE, Madrid-Bury N, Quintero-Moreno A. Effects of cryopreservation on bull spermatozoa distribution in morphometrically distinct subpopulations. Reprod Dom Anim 2007;42:354-7. [50] Vicente-Fiel S, Palacín I, Santolaria P, Yániz JL. A comparative study of sperm morphometric subpopulations in cattle, goat, sheep and pigs using a computer-assisted fluorescence method (CASMA-F). Anim Reprod Sci 2013;139:182-9.

[51] Martí JI, Aparicio IM, García-Herreros M. Sperm morphometric subpopulations are differentially distributed in rams with different maturity age in cryopreserved ejaculates. Theriogenology 2011;76:97-109.

[52] Harrison RAP. Capacitation mechanisms and the role of capacitation as seen in eutherian mammals. Reprod Fertil Dev 1996;8:581-94.

[53] Abaigar T, Holt W, Harrison R, del Barrio G. Sperm subpopulations in boar (Sus scrofa) and gazelle (Gazella dama mhorr) semen as revealed by pattern analysis of computer-assisted motility assessments. Biol Reprod 1999;60:32-41.

[54] Gomendio M, Roldan ERS. Implications of diversity in sperm size and function for sperm compeititon and fertility. Int J Dev Biol 2008;52:439-47. 
438 [55] Martin-Coello J, Dopazo H, Arbiza L, Ausió J, Roldan ER, Gomendio M. Sexual selection

439 drives weak positive selection in protamine genes and high promoter divergence, enhancing

$440 \quad$ sperm competitiveness. Proc Biol Sci 2009; 27:2427-36.

441 [56] Fisher HS, Joekstra HE. Competition drives cooperation among closely related sperm of

442 deer mice. Nature 2010;463:801-3.

443 [57] Lincoln GA. Seasonal cycles in testicular activity in Mouflon, Soay sheep and domesticated

444 breeds of sheep: breeding seasons modified by domestication. Zool J Linn Soc 1989; 95:137-47.

445 [58] Humphries S, Evans J. Simmons L. Sperm competition: linking form to function. BMC Evol

446 Biol 2008;8:319.

447 
465

466

467

468

469

470

471

Fig. 1. Distribution of sperm subpopulations in ram based on head morphometry. Four head morphometry sperm subpopulations were identified: SP1 (large and round), SP2 (short and elongated), SP3 (shortest and round) and SP4 (large and the most elongated).

Fig. 2. Relationship between the percentage of spermatozoa with long and wide heads (SP1), short and elongated heads (SP2), shortest head dimensions and wide (SP3) and longest head with the highest $\mathrm{p} 2 \mathrm{a}(\mathrm{SP} 4)$ of ram ejaculates and fertility after artificial insemination. A total of 83 rams were used with a total of 1024 ewes inseminated $(P<0.001)$. Adjusted fertility data are drawn (fertility values could be over 100\% after statistical correction; for more information see materials and methods).

(1)

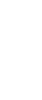

(1) 
472 Table 1. Morphometric characteristics of each sperm subpopulation defined in ejaculates of Manchega rams. Data are expressed as mean \pm SD.

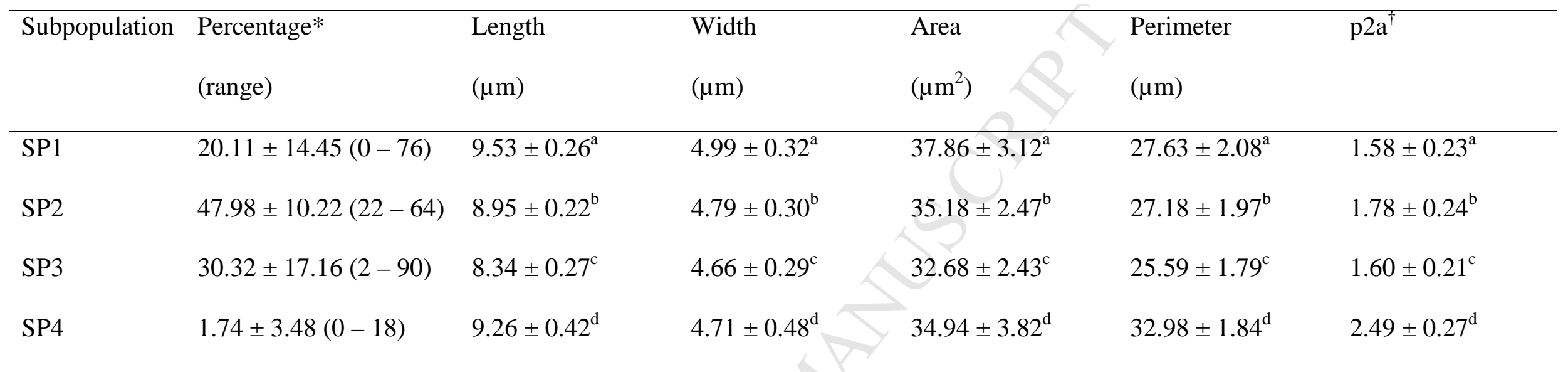

473 * Percentage of spermatozoa in each subpopulation. Different superscript indicate significant differences between sperm subpopulations.

$474 \dagger \mathrm{p} 2 \mathrm{a}=$ perimeter $^{2} / 4 \cdot \pi \cdot$ Area. 
475 Fig 1. Maroto Morales et al.

476

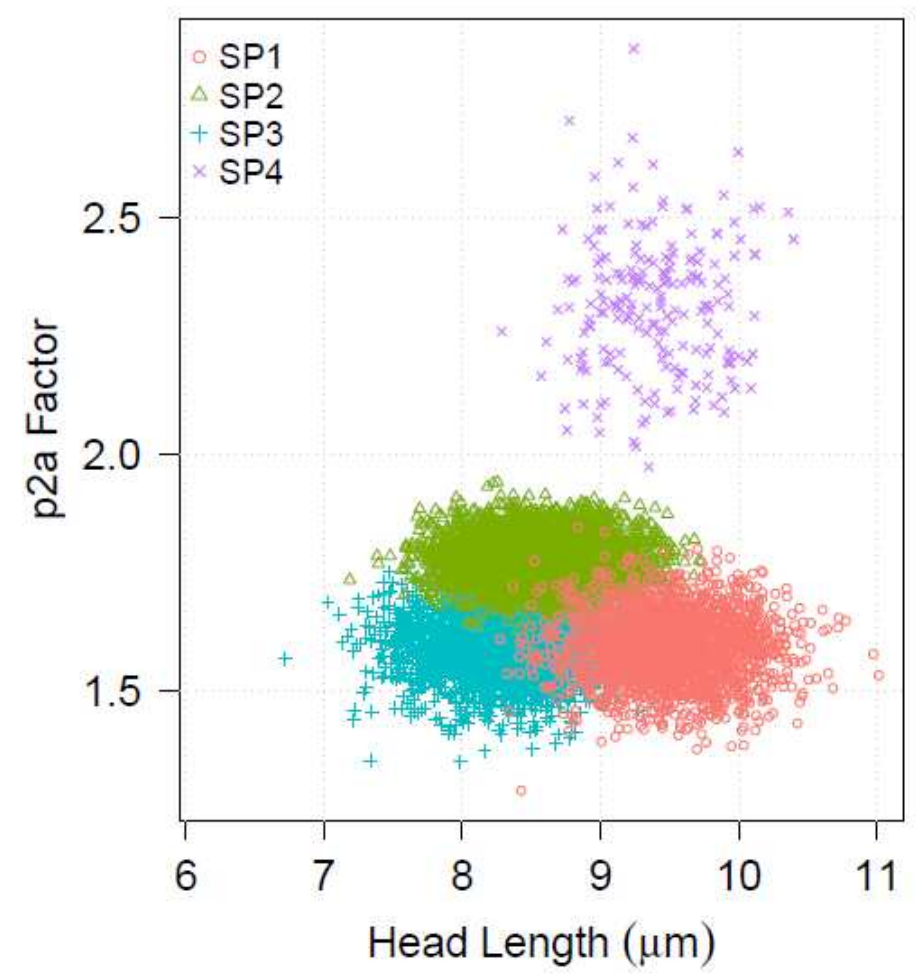

477

478

479

480

481

482

483

484

485

486

487 
489 Fig. 2. Maroto Morales et al.

490

a)

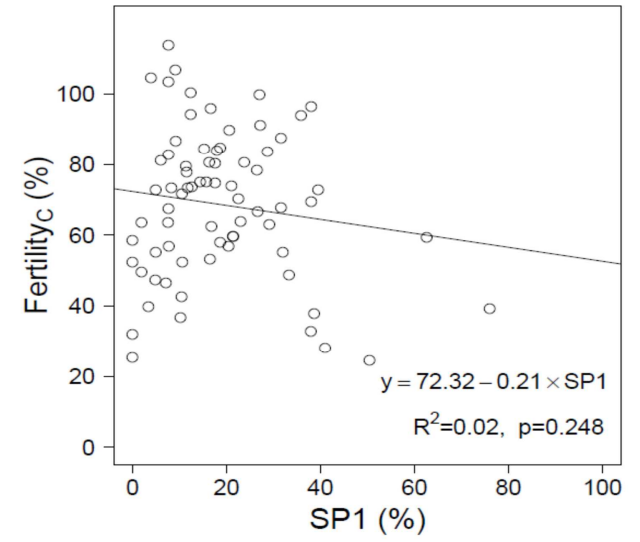

c)

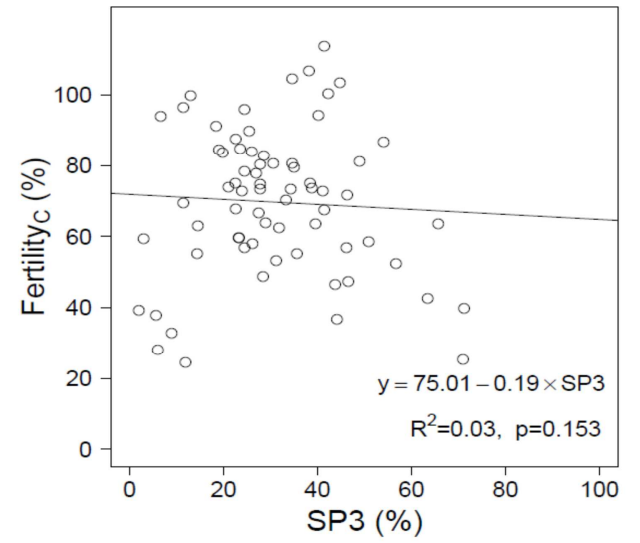

b)

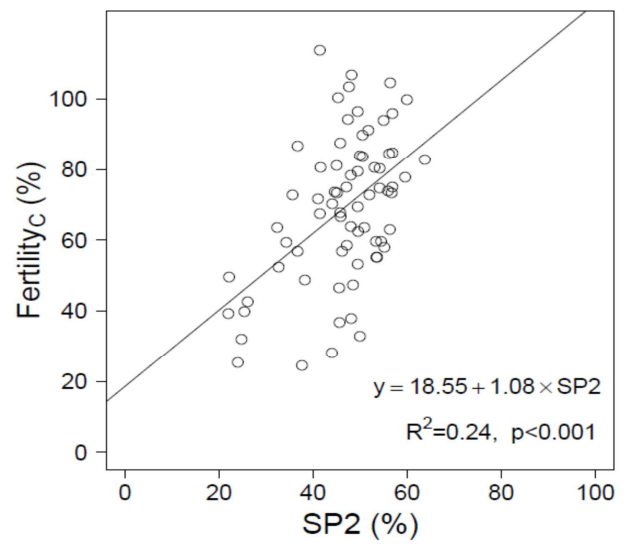

d)

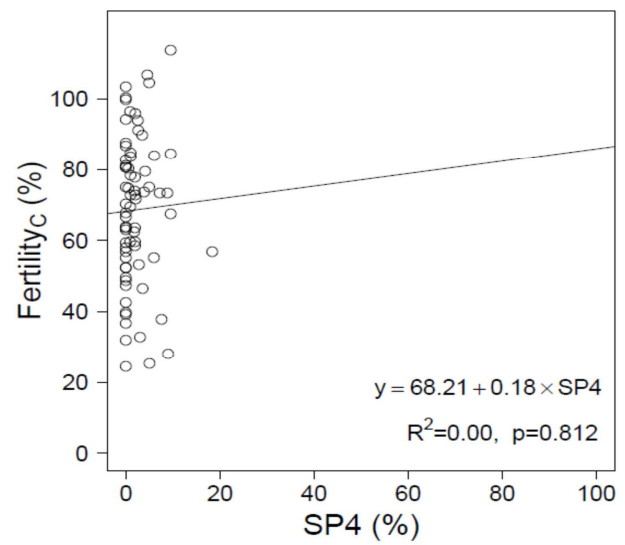

491 